\title{
A TEM Study of Birnessite-type $\mathrm{K}_{0.33} \mathrm{MnO}_{2}$ - In-plane Ordering and Layer Stacking -
}

\author{
Noriaki Nakayama, Katsuhiro Ohmoto, Keiko Fujiwara, and Akihiko Nakatsuka \\ Graduate School of Science and Engineering, Yamaguchi University, Ube 755-8611, Japan \\ "nakayamn@yamaguchi-u.ac.jp
}

\begin{abstract}
Birnessite-type $\mathrm{K}_{0.33} \mathrm{MnO}_{2}$ was prepared by the solid state reaction of $\mathrm{KOH}$ and $\mathrm{MnCO}_{3}$ in air. The XRD pattern of the sample calcined at $700^{\circ} \mathrm{C}$ can be indexed as a single phase of the monoclinic $C 2 / \mathrm{m}$ phase ( $\left.a=5.186 \AA, b=2.851 \AA, c=7.154 \AA, \beta=101.74^{\circ}\right)$. Their $[001]_{\mathrm{m}}$ zone ED patterns show superlattice spots indicating in-plane pseudo-hexagonal $(\sqrt{3} \times \sqrt{3})_{\mathrm{h}}-\mathrm{R} 30^{\circ}$ and monoclinic $(3 \times 1)_{\mathrm{m}}$ ordering. However, the lattice images do not show clear contrast of the superlattice. Although the $[010]_{\mathrm{m}}$ and $[100]_{\mathrm{m}}$-zone ED patterns also showed clear superlattice spots, they show diffuse streaks due to the stacking disorder. The lattice images clearly revealed the details of the layer stacking. The thickness of the layers with the regular stacking is limited to several nano-meters because of the stacking disorder.
\end{abstract}

keywords: layered structure, in-plane superlattice, electron diffraction, lattice image, stacking disorder

\section{INTRODUCTION}

Layered birnessite-type manganese oxides, $\mathrm{A}_{\mathrm{x}} \mathrm{MnO}_{2}$ (A: mono-valent or di-valent metals), have been long investigated as ion-exchangers, oxidative catalysts and so on [1]. The birnessite-type crystal structure is composed of $\mathrm{CdI}_{2}$ or brucite type $\mathrm{MnO}_{2}$ layers, of which interlayers are occupied by cations and water molecules. The interlayer spacing is about $0.7 \mathrm{~nm}$. The $\mathrm{Mn}$ atoms are in the mixed valence state; the average valence is in between 3 and 4 depending on the species and the content of $\mathrm{A}$ atoms. The content of A cations ranges from $x=$ 0.2 to 0.5 when A cation is an alkaline metal, depending on the sample preparation methods. Although the fundamental structure of birnessite-type manganese oxides is simple, the actual structure is rather complicated. The several crystal symmetries have been reported; the fundamental hexagonal, monoclinic and triclinic ones[2-7]. It may be caused by the non-stoichiometry of A cations and/or water molecules, and also the variety of layer stacking.

Several researchers have reported electron diffraction (ED) studies $[2,8,9]$ on the in-plane chemical ordering and have proposed its models of the interlayer cationic ordering, the charge ordering of $\mathrm{Mn}^{3+}$ and $\mathrm{Mn}^{4+}$, and/or the vacancy ordering in the $\mathrm{Mn}$ sites. However, the details of the superstructure, the composition dependence and the layer stacking etc., are not clear. The weak XRD intensity of the superlattice reflection in spite of the clear electron diffraction spots suggest that the ordering is short-ranged and the layer stacking is disordered. To reveal the above structural features, the high resolution lattice image observations using transmission electron microscopy (TEM) are desired. To our knowledge, no such TEM study has been reported, probably because the thin plate-like morphology prevents the lattice image observations of layer stacking.

In this paper, we report a high resolution transmission electron microscopy (TEM) study on birnessite-type $\mathrm{K}_{0.33} \mathrm{MnO}_{2}$. Samples were prepared by a solid state reaction of $\mathrm{KOH}$ and $\mathrm{Mn}_{2} \mathrm{O}_{3}$ in air, because the relatively small in-plane size of the crystallites prepared by this method is preferable for the observation of the layer stacking. The potassium compound was selected because it shows relatively simple in-plane ordering $[2,8]$.

\section{EXPERIMENTAL}

Samples were prepared by the solid state reaction of $\mathrm{KOH}$ and $\mathrm{Mn}_{2} \mathrm{O}_{3}$. The nominal compositions are in the range $0.25 \leq$ $x \leq 0.5$ in the formula of $\mathrm{K}_{\mathrm{x}} \mathrm{MnO}_{2}$. Samples are heated in air in the temperature range from 500 to $1000{ }^{\circ} \mathrm{C}$ for 2 days. Samples were characterized by using a powder XRD method using $\mathrm{Cu}-K \alpha$ radiation.

The electron diffraction patterns and the lattice images were obtained by using a field emission type $200 \mathrm{kV}$ transmission electron microscope (JEOL 2010F). The image processing and analyses were performed by using two public domain graphic programs, the NIH ImageJ version $1.34 \mathrm{e}$ [10] and EDM2.01 [11] software packages.

\section{RESULTS AND DISCUSSIONS \\ 3.1 Powder XRD patterns}

Figure 1 shows powder $\mathrm{x}$-ray diffraction patterns of the samples heated at $700^{\circ} \mathrm{C}$. The nominal compositions are $x=$ $0.3,0.33,0.4,0.45$ and 0.50 in the formula of $\mathrm{K}_{x} \mathrm{MnO}_{2}$. All of them show sharp and intense 001 and 002 peaks of layered birnessite-type structure. In the higher angle $2 \theta$ range, weak and somewhat broad peaks are seen. In the case of sample with the nominal composition of $x=0.33,0.40$ and 0.45 , all the peak except a peal at around $2 \theta=32^{\circ}$ are indexed as those of a monoclinic birnessite-type structure. The broad peaks at around $2 \theta=32^{\circ}$ may be attributed to the main peak of $\mathrm{K}_{2} \mathrm{CO}_{3}$, which shows several polymorphs. For the sample with $x=0.30$ and 0.50 , the peaks of impurity phases $\mathrm{K}_{2} \mathrm{MnO}_{4}$ (marked by filled circles) and hollandite-type $\mathrm{K}_{x} \mathrm{Mn}_{8} \mathrm{O}_{16}$ (marked by filled squares) are seen. When samples were heated at 500, 600, 800 and $900{ }^{\circ} \mathrm{C}$, peaks of similar impurity phases appeared in the XRD patterns.

In the XRD pattern of the sample with $x=0.33$, the peaks of impurity phases are weak and the peaks are fairly sharp. Therefore this sample is well assumed as nearly single phase material. The lattice parameters of this sample, assuming the 


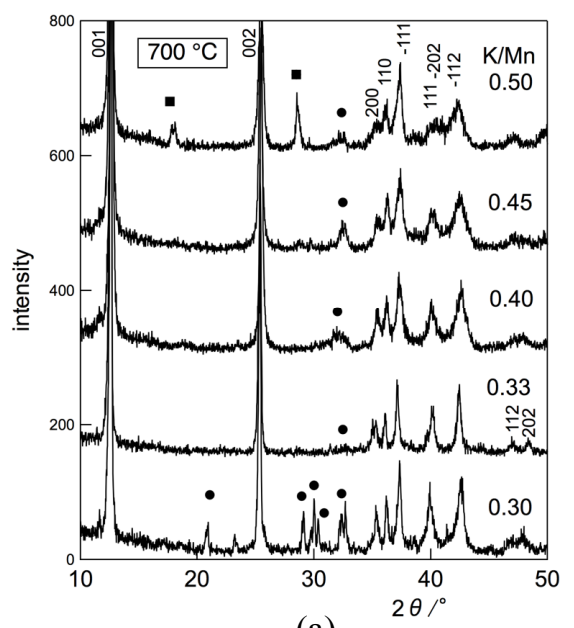

(a)

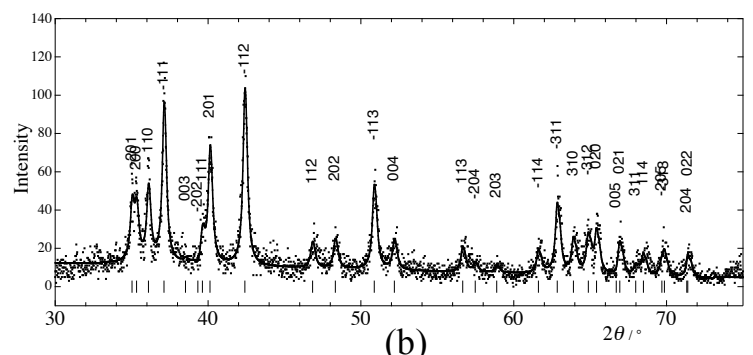

(b)

Fig. 1 Powder XRD patterns of samples prepared at $700{ }^{\circ} \mathrm{C}$. (a) samples with the nomical composition $x=0.30$, $0.33,0.400 .45$, and 0.50 , in $\mathrm{K}_{\mathrm{x}} \mathrm{MnO}_{2}$, and (b) The fitted profile using a kind of Powley method for the sample with $x=0.33$, assuming the monoclinic $C 2 / m$ symmetry.

monoclinic $C 2 / m$ symmetry, were determined by a Powley method [12] using the peaks appearing in the $2 \theta$ range from 30 to $75^{\circ}$. The fitted lattice parameters are $a=5.184 \AA, b=2.851$ $\AA, c=7.154 \AA$ and $\beta=101.74^{\circ}$. The layer spacing $c \sin \beta$ is $7.004 \AA$ and the in-plane distortion is $a / \sqrt{3} b=1.050$. The values are almost agree with the results of the previous studies by Post $\&$ Veblen [2]; $a=5.149 \AA, b=2.843 \AA, c=7.176 \AA$, $\beta=100.76^{\circ}, c \sin \beta=7.050 \AA$, and $a / \sqrt{ } 3 b=1.046$ for $\mathrm{K}_{0.23} \mathrm{MnO}_{2} \cdot\left(\mathrm{H}_{2} \mathrm{O}\right)_{0.8}(68918$-ICSD) and by Gaillot et al. [5]; $a=$ $5.130 \AA, b=2.850 \AA, c=7.131 \AA$ and $\beta=100.8^{\circ}, c \sin \beta=$ $7.005 \AA, a / \sqrt{3} b=1.039$ for $\mathrm{K}_{0.312} \mathrm{Mn}_{0.976} \mathrm{O}_{2} \cdot\left(\mathrm{H}_{2} \mathrm{O}\right)_{0.37}$ (152294-ICSD). TEM observations were mainly performed for this sample.

\subsection{TEM observations of in-plane structure}

Figure 2(a) shows a low magnification bright field image of the sample with the nominal composition of $x=0.33$ and heated at $700{ }^{\circ} \mathrm{C}$. The sample is composed of thin plate-like crystallites, of which diameters are in the range from 100 to $500 \mathrm{~nm}$. Figure 2(b) shows the energy dispersive $\mathrm{x}$-ray (EDX) spectrum of a crystallite marked by the circle in Fig.2(a). The compositional ratio of $\mathrm{K} / \mathrm{Mn}$ is 0.34 , which agrees with the nominal composition. Other crystallites showed similar EDX spectra.

Figure 3 shows an $[001]_{\mathrm{m}}$ zone electron diffraction pattern (EDP) taken from the crystallite similar to the one marked by a circle in Fig. 2(a). It shows intense diffraction spots of monoclinic fundamental lattice with $C 2 / m$ symmetry. In addition of fundamental spots, many extra spots are seen. Relatively intense spots appears at $\boldsymbol{g}^{*}(0,2 / 3,0), \boldsymbol{g} *(1,1 / 3,0)$

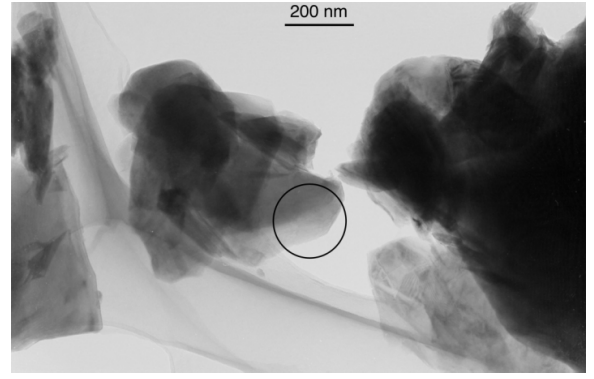

(a)

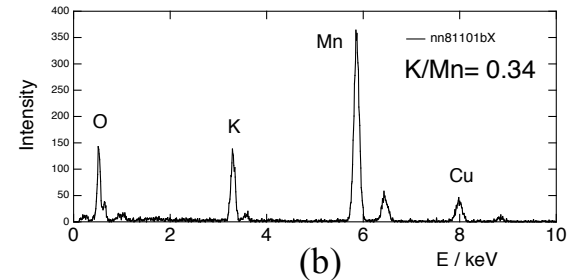

Fig. 2 Typical low magnification TEM images and the EDX spectrum of a typical crystallite marked in the image.

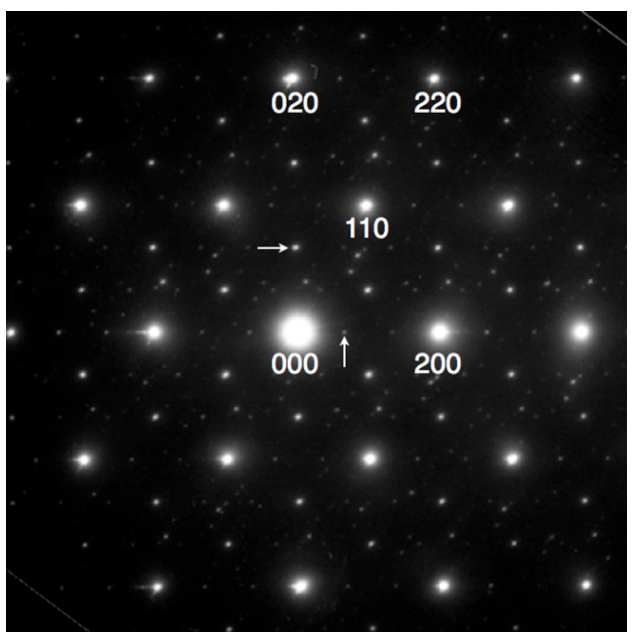

Fig. 3 An $[001]_{\mathrm{m}}$ zone EDP of the thin flat crystallite. Some of the fundamental spots are indexed according the monoclinic $C 2 / m$ unit cell deduced from the powder XRD pattern. Many superlattice spots are seen as marked by arrows.

and the equivalent reciprocal lattice points. Based on the more fundamental tri-angular in-plane lattice, these spots are noted as the $[\sqrt{ } 3 \times \sqrt{ } 3] R 30^{\circ}$ superlattice spots [13]. We denote this type of superlattice spots as $[\sqrt{ } 3 \times \sqrt{3}]_{\mathrm{h}}$ order spots. Another type of superlattice spots appear at $g^{*}(1 / 3,0,0)$ and the equivalent positions. We denote this type of spots as $[3 \times 1]_{\mathrm{m}}$ ordered spots. The diffraction pattern is rather complex due to the twining and the overlap of different crystallites.

Figure 4(a) shows a typical high resolution lattice image with the $[001]_{\mathrm{m}}$ incidence. The image shows fine contrast of the fundamental $C 2 / m$ lattice with the lattice dimension of about $0.28 \times 0.52 \mathrm{~nm}$. Overlapped with this contrast, the weak contrast modulations with the period of about $0.56 \mathrm{~nm}$ and 0.75 $\mathrm{nm}$, corresponding to the $[\sqrt{ } 3 \times \sqrt{3}]_{\mathrm{h}}$ and $[3 \times 1]_{\mathrm{m}}$ ordered spots respectively, are seen as marked in the image. The Fourier transform of the image shows clear spots due to the superlattices. To see the details of the superlattice ordering, the observed image was processed by Fourier filtering using band 

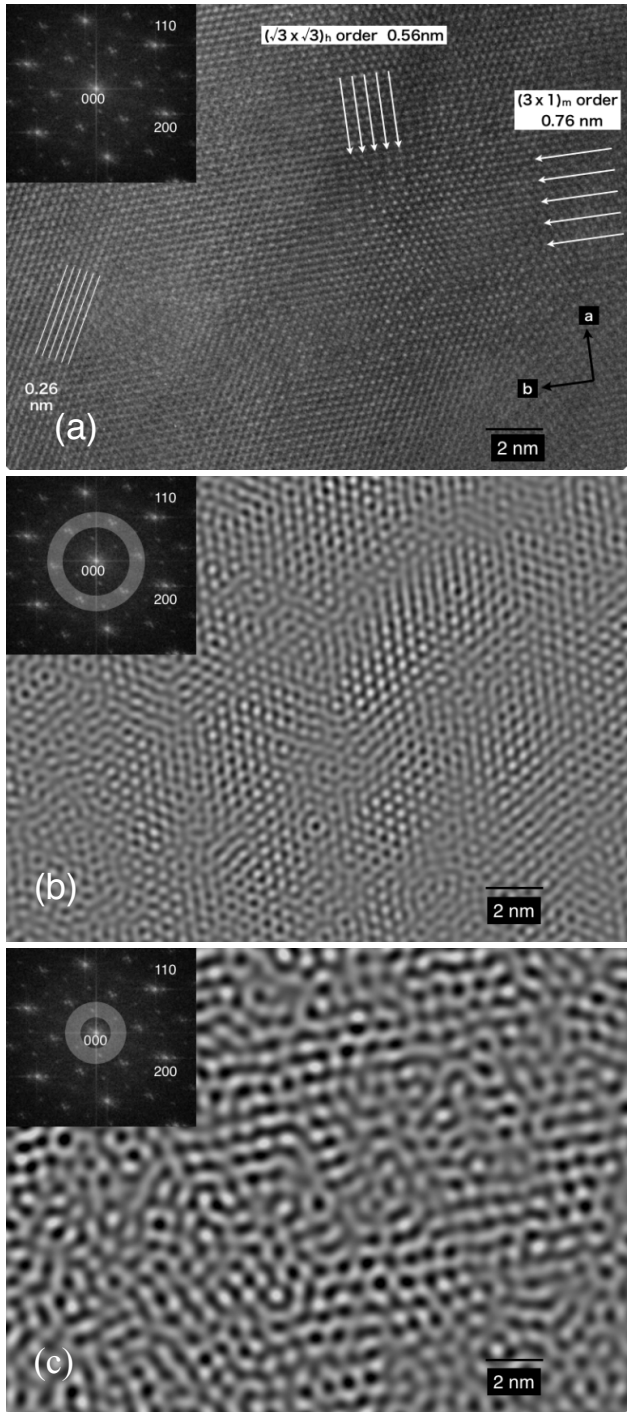

Fig. 4 High resolution lattice images with $[001]_{\mathrm{m}}$ incidence.(a) The original image, of which Fourier transform (power spectrum) is shown in the inset. (b) A Fourier filtered image obtained by placing the radial mask covering $[\sqrt{ } 3 \times \sqrt{3}]_{\mathrm{h}}$ order spots. (c) A Fourier filtered image obtained by placing the radial mask covering $[3 \times 1]_{\mathrm{m}}$ order spots.

path filters. Figure $4(\mathrm{~b})$ shows the band path filtered image using the radial mask covering the $[\sqrt{ } 3 \times \sqrt{3}]_{\mathrm{h}}$ order spots in the range $\mathrm{d}^{*}$ from 1.5 to $2.0 \mathrm{~nm}^{-1}$. The Fourier filtered image shows the clear contrast of $[\sqrt{ } 3 \times \sqrt{3}]_{h}$ ordering. However it is limited to the narrow regions of about a few nm sized and the phase shift among the ordered domains is observed. A similarly Fourier filtered image for the $[3 \times 1]_{\mathrm{m}}$ ordered spots are shown in Fig. 4(c). The image shows the fringe pattern of the spacing about $0.75 \mathrm{~nm}$. However, it indicates that the ordering is more short-ranged.

\subsection{TEM observations of the layer stacking}

Figure 5(a) shows a low magnification image of an aggregate of crystallites containing a standing one marked by a circle. This type of standing crystallite gives the EDPs containing $c^{*}$ reciprocal axis. The $[010]_{\mathrm{m}}$ zone EDP in Fig. 5(b) was taken for the standing crystallite shown in Fig. 5(a). Weak superlattice spots appear, dividing the distance between 000 and 200 spots into three equal parts. These superlattice spots agree with the
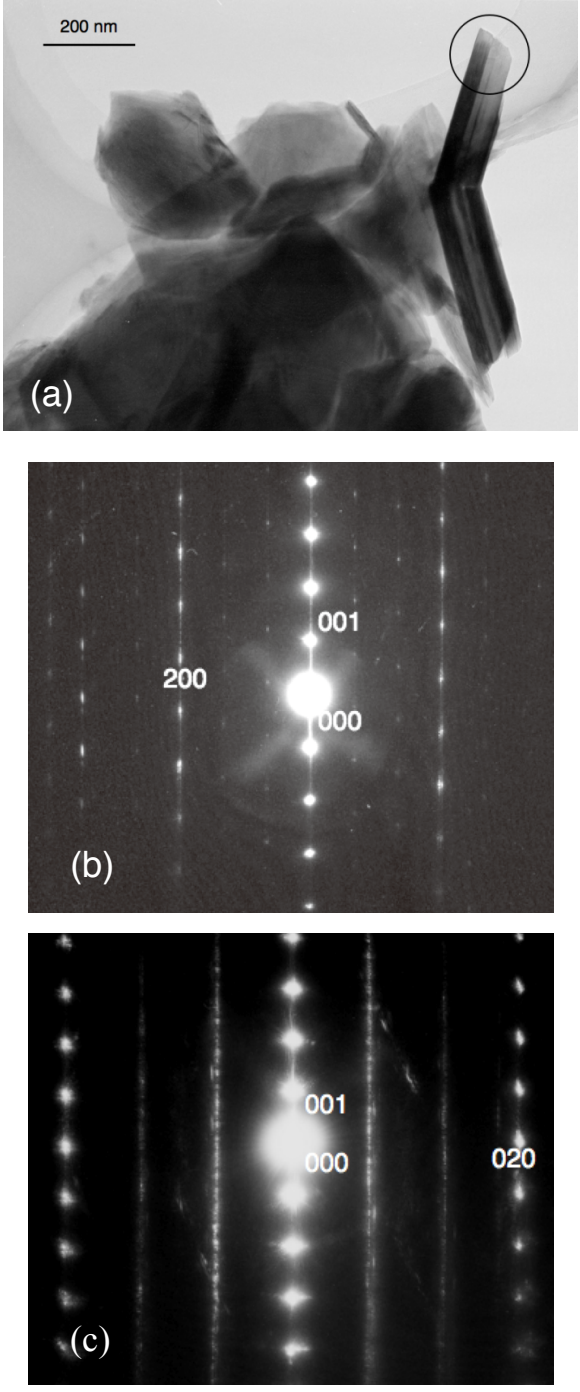

Fig. 5 A low magnification image of an aggregate of crystallites containing standing ones as marked by circle (a) and EDPs taken from such standing crystallites; (b) $[010]_{\mathrm{m}}$ and (c) $[100]_{\mathrm{m}}$ zone EDPs.

$[3 \times 1]_{\mathrm{m}}$ ordered spots in the $[001]_{\mathrm{m}}$ zone EDP. However, the EDP shows diffuse streaks parallel to the $c^{*}$ direction even for the fundamental spots, indicating stacking disorder of the fundamental lattice. The $[100]_{\mathrm{m}}$ zone EDP taken for another standing crystallite shows fairly intense diffuse streaks along $\mathrm{c}^{*}$. They divide the distance of $(00 L)^{*}$ and $(02 L)^{*}$ reciprocal row into the three equal parts. These diffuse streaks agree with the $[\sqrt{3} \times \sqrt{3}]_{\mathrm{h}}$ ordered spots in the $[001]_{\mathrm{m}}$ zone EDP. The diffuse streak shows some intensity variations indicating partial ordering. Anyway, the EDP indicates that the stacking of in-plane $[\sqrt{3} \times \sqrt{3}]_{\mathrm{h}}$ ordering shows severe disorder.

Figure 6 shows two lattice images viewed along $[010]_{\mathrm{m}}$ and $[100]_{\mathrm{m}}$, of which EDPs are shown in Fig. 5 (b) and (c), respectively. The Fourier transforms of the images shown as the inset in each figure well agree with the observed EDPs. In both images, clear $(001)_{\mathrm{m}}$ lattice fringes with the spacing about $0.7 \mathrm{~nm}$ are seen. Some irregularity in the $(001)_{\mathrm{m}}$ lattice fringe is seen as marked by white arrows in Fig. 6. They may be caused by the stacking disorder of the pseudo-hexagonal monoclinic lattice (or in other word $\mathrm{MnO}_{2}$ layers). Figure 6(a) viewed along $[010]_{\mathrm{m}}$ shows the clear dot contrast with the 

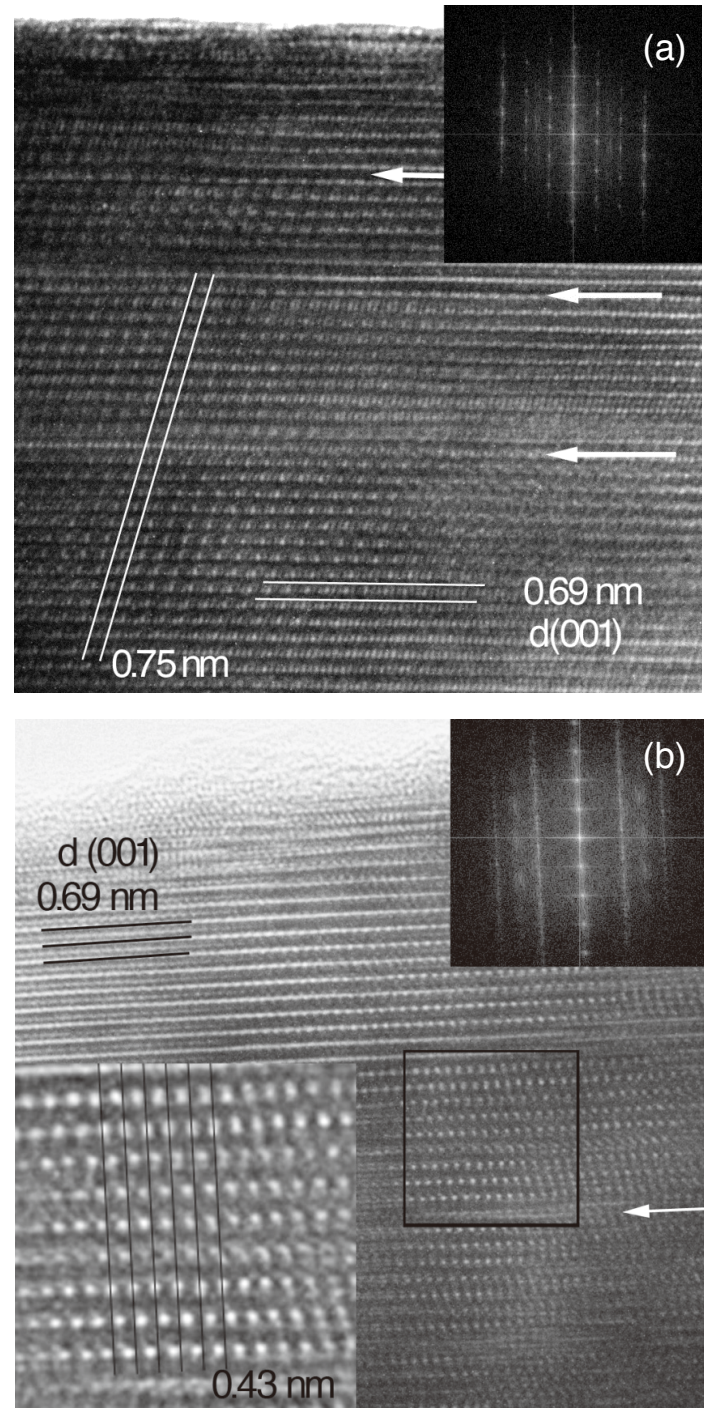

Fig. 6 Lattice images of $\mathrm{K}_{0.33} \mathrm{MnO}_{2}$ viewed along (a) $[010]_{\mathrm{m}}$ and $(\mathrm{b})[100]_{\mathrm{m}}$ directions. The white arrows indicate the stacking disorder. The Fourier transforms of the images are shown in the insets.

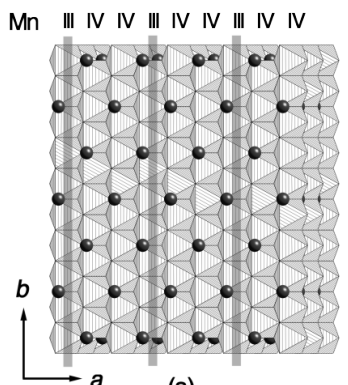

(a)

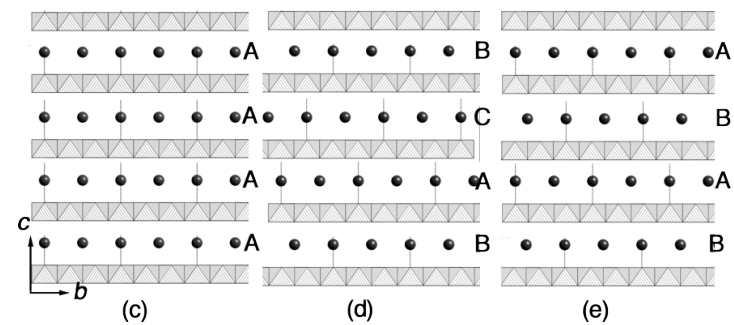

Fig. 7 Model structures of the superlattice. spacing of $0.75 \mathrm{~nm}\left(1.5\right.$ times of $\left.a_{\mathrm{m}}\right)$ along the $[100]_{\mathrm{m}}$ direction, which corresponds to the $[3 \times 1]_{\mathrm{m}}$ ordered spots in the EDP. However, its phase in the $c$-plane is shifted across the stacking faults marked by white arrows. The region with the regular dot contrast is limited. The similar dot contrast is seen in the image viewed along $[100]_{\mathrm{m}}$. The spacing of white dot along [020] is regular and about $0.43 \mathrm{~nm}$, corresponding to 3 times of $d(020)_{\mathrm{m}}$. However, the nearly random in-plane phase shift is seen in each layer. The region marked by a rectangle in Fig. 6 (b) was enlarged as an inset, which indicates a BCABBBCAB-type stacking.

\subsection{A model structure of the superlattice}

According to the literatures $[2,9]$, the $[\sqrt{ } 3 \times \sqrt{ } 3]_{\mathrm{h}}$-type and $[3 \times 1]_{\mathrm{m}}$-type superlattices are attributed to the $\mathrm{K}$ atom ordering and the charge ordering of $\mathrm{Mn}(\mathrm{III})$ and $\mathrm{Mn}(\mathrm{IV})$, respectively, of which in-plane model structure is described in Fig. 7(a). The stacking of the Mn charge ordering revealed by the present TEM observations are shown in Fig. 7(b). The one dimensional $\mathrm{Mn}(\mathrm{III})$ arrays are stacked along c-axis. The stacking of $[\sqrt{ } 3 \times$ $\sqrt{ } 3]_{\mathrm{h}}$-type ordered $\mathrm{K}$ layers is nearly random; the three types of stacking, AAAA-, ABCABC-, and ABAB-, as shown in Fig. 6 (c), (d), and (e), respectively, are mixed. The unit cell of the superlattice deduced from the present observation is a monoclinic one with the unit cell dimension of $\boldsymbol{a}=3 \boldsymbol{a}_{\mathrm{m}}, \boldsymbol{b}=$ $3 \boldsymbol{b}_{\mathrm{m}}$, and $\boldsymbol{c}=\boldsymbol{c}_{\mathrm{m}}$., where $\boldsymbol{a}_{\mathrm{m}}, \boldsymbol{b}_{\mathrm{m}}$, and $\boldsymbol{c}_{\mathrm{m}}$ are unit vectors of the fundamental $C 2 / m$ monoclinic lattice.

\section{SUMMARY}

The superstructure of the $\mathrm{K}_{0.33} \mathrm{MnO}_{2}$, previously reported by the electron diffraction studies $[2,8]$, was revealed by the high resolution lattice image observations for the first time in the present study. The ordering in each layer seems to be almost regular, although in-plane lattice images seem to be short range ordered. Such a short range nature may be attributed to the stacking disorder mainly for the $[\sqrt{ } 3 \times \sqrt{3}]_{\mathrm{h}}$-type ordered $\mathrm{K}$ layers.

\section{REFERENCES}

1) J. Liu, J. P. Durand, L. Espinal, L-J. Garces, S. Gomez, Y-C. Son, J. Villegas and S. L. Suib, in Handbook of Layered Materials, edited by S. M. Auerbach, K. A. Carrado and P.K. Dutta, Marcel Dekker Inc., New York, Basel, (2004) pp.475-508.

2) J. E. Post and D. R. Veblen, Am. Mineal., 75, 477 (1990).

3) V. A. Drits, E. Silvester, A. I. Gorshokov, and A. Manceau, Am. Mineral., 82, 946 (1997).

4) B. Lanson, V. A. Drits, Q. Feng, and A. Manceau, Am. Mineral., 87, 1662 (2002).

5) A-C Gaillot, B. Lanson, and V. A. Drits, Chem. Mater. 17, 2959 (2005).

6) A-C Gaillot, V. A. Drits, A. Planc and B. Lanson, Chem. Mater.,16, 1890 (2004).

7) A-C Gaillot, V. A. Drits, A. Manceau, and B. Lanson, Micropor. Mesopor. Mater., 98, 267 (2007).

8) K. Kuma, A. Usui, W. Paplawsky, B. Gedulin and G. Arrhenius, Mineal. Mag., 58, 425 (1994).

9) V. A. Drits, B. Lanson, A. I. Gorshkov, and A. Manceau, Am. Mineral. 83, 97 (1998).

10) W. Rasband, ImageJ, http://rsb.info.nih.gov/ij/.

11) R. Kilaas, C. Own, K. Tsuda, W. Sinkler and L. Marks, EDM: Electron direct methods, http://www.numis.northwestern.edu/edm/; R. Kilaas, L.D. Marks, and C.S. Own, Ultramicroscopy, 102, 233 (2005).

12) G. S. Pawley, J. Appl. Crystallogr., 14, 357 (1981).

13) C. Delmas, C. Fouassier, and P. Hagenmuller, Physica B, 99, 81 (1980).

(Received January 20, 2010; Accepted May 10, 2010) 